\title{
Sensor Comparison for Corona Discharge Detection Under Low Pressure Conditions
}

\author{
Jordi-Roger Riba, Álvaro Gómez-Pau, and Manuel Moreno-Eguilaz
}

\begin{abstract}
Low pressure environments, situate insulation systems in a challenging position since partial discharges (PDs), corona and arc tracking are more likely to develop. Therefore, specific solutions are required to detect such harmful phenomena before major failure occurrence. This paper deals with three low-cost and small-size sensing methods, i.e., a single loop antenna, a visible-UV imaging sensor and the measurement of the leakage current to detect corona in the early stage, thus anticipating the appearance of severer effects such as arc tracking or disruptive breakdown. The three studied methods can be applied for an on-line monitoring of corona activity under low pressure environments, thus being compatible with predictive maintenance approaches. This on-line monitoring can be used to develop improved electrical protection devices able to detect such effects in an initial stage, thus improving current solutions which are unable to do so. All three studied sensors give consistent linear responses within the studied pressure range, i.e., 10-100 kPa, with almost no drift. The sensitivity of the visible-UV imaging sensor is slightly lower than that of the others, but it has the advantage of directly locating the discharge points. Results presented in this paper can be very useful for the more electrical aircraft (MEA), which is forcing electrical distribution systems to operate at higher voltage levels. Due to the little experience and scarcity of published data, the experimental results presented in this paper can be valuable for a better understanding of the combined action of high voltage and low pressure environments.
\end{abstract}

Index Terms - Partial discharge, corona effect, high-voltage, antenna sensor, ultraviolet, imaging sensor, sensor low pressure, leakage current.

\section{INTRODUCTION}

$\mathrm{T}_{\mathrm{t} \text { tes }}$ HERE is a growing interest in understanding and quantifying the combined effects of low pressure and high-voltage due to the progressive development of the next generation of more electrical aircrafts (MEA). The MEA concept involves increasing overall aircraft efficiency while reducing greenhouse gas emissions, by replacing onboard mechanic, hydraulic and pneumatic systems [1] by lighter electrical ones, thus requiring increased levels of electrical power than conventional aircrafts [2]. Aircraft electrification offers other appealing features, since it allows reducing the overall weight of the aircraft [1], fuel consumption, system complexity or operation and maintenance costs. Due to weight constraints, this more intensive use of electrical power forces aircraft electrical transmission systems operating at increased voltages [3], [4]. Conventional cruising altitudes of commercial jet aircrafts are in the range $10-13 \mathrm{~km}$, private jets can fly at altitudes below $15 \mathrm{~km}$, and some military aircrafts can fly beyond $15 \mathrm{~km}$. This broad range of altitudes implies a pressure interval from $100 \%$ to $15 \%$ of the atmospheric pressure at sea level. Aircrafts operate under extreme environmental conditions [5], and some electrical and electronic circuits are unpressurized areas. The combined effect of extreme environmental conditions and the higher electric stress resulting from the increased voltage levels [1], [6] poses insulations systems in a challenging situation. Some aircraft

This work was supported in part by the Generalitat de Catalunya under Project 2017 SGR 967 \& in part by the Spanish Ministry of Science and Innovation under Project RTC-2017-6297-3.

J.-R. Riba is with the Universitat Politècnica de Catalunya, Electrical Engineering Department, Rambla Sant Nebridi 22, 08222 Terrassa, Spain (e-mail: riba@ee.upc.edu) manufacturers are planning electrical distribution systems working above $1 \mathrm{kV}$, and even in the $1.5-4.5 \mathrm{kV}$ range, thus promoting partial discharges (PDs), corona and arc tracking inception conditions [7]. Since the NASA missions of the 1960 s, it is known that partial PDs are more likely to occur in electrical and electronic systems operating at lower pressures [6], [8], so spark breakdown, PD and corona inception voltage values found in low pressure environments are considerably lower when compared to those found at sea level [1]. Other factors found in aeronautic applications, such as moisture condensation [9], or other contaminants such as liquids, salts or conductive dusts [10] can also play an important role. As a consequence, due to reliability and safety considerations, it is mandatory to limit the risk of PD, corona and arcing occurrence, this being a challenging task for power system and wiring designers, due to the strict compactness and lightness requirements of aircraft power systems [1]. By limiting the risk of such harmful effects, the reliability of electrical, electronic and wiring systems can be increased, thus limiting failure occurrence and facilitating the application of predictive maintenance plans [8], together with an overall increase of the aircraft safety. Therefore, the continuous monitoring of the corona activity allows predictive maintenance plans to be applied, so corrective actions can be taken before the development of major dielectric failures [11] can lead to catastrophic consequences.

A. Gómez-Pau is with the Universitat Politècnica de Catalunya, Electronic Engineering Department, Rambla Sant Nebridi 22, 08222 Terrassa, Spain (e-mail: alvaro.gomez-pau@upc.edu)

M. Moreno-Eguilaz is with the Universitat Politècnica de Catalunya, Electronic Engineering Department, Rambla Sant Nebridi 22, 08222 Terrassa, Spain (e-mail: manuel.moreno.eguilaz@upc.edu) 
A deep knowledge about corona inception conditions is needed to design power system components minimizing electrical discharge occurrence under low pressure conditions. Accurate prediction of inception conditions under low pressure environments, requires extensive testing and experimental data. Therefore, it is required to develop inexpensive and small size sensors to detect corona activity to safeguard the integrity and long-term behavior of insulation materials and systems for low pressure applications. This strategy is focused to detect discharge related issues in the very early stage, thus preventing the development of major failures, since corona activity unavoidably weakens electrical and mechanical properties of insulation materials with the consequent threat to the safety of the aircraft as well as to its electrical and electronic systems [12]. However, there are few works systematically investigating PD or corona behavior under low pressure conditions (10-100 $\mathrm{kPa}$ ) [13], since most of them analyze arcing [14] or disruptive breakdown conditions [15]-[17], i.e., when the effects of the electrical discharges are very advanced, thus increasing the likelihood of catastrophic faults. This paper makes a contribution in the area of early corona detection under low pressure conditions, i.e., $100 \%$ to $10 \%$ of the standard pressure. To this end, corona discharges of a point-to-plane gap are detected by means of three sensing methods, including a single loop antenna, a visible-UV imaging sensor and by measuring the leakage current due to the discharges. The three analyzed methods can be applied for an on-line detection and monitoring of corona activity in the very early stage, thus allowing to apply corrective actions and preventing the development of major damages and critical failures. This paper is also focused to prevent and anticipate arc tracking occurrence and thus the related hazards, in wiring and electrical and electronic insulation systems. This is of special importance as current commercial protections such as arc fault circuit breakers or solid state power controllers cannot detect arc tracking activity in the early stage because of the low level of the initial leakage current, which is below the detection limit of conventional circuit breakers. This problem can remain invisible to the protections, although the induced overheating in the insulation due to this hidden effect increases with time. The proposed approach can be very useful to track the evolution of the discharges, thus allowing to apply predictive maintenance plans and trip the circuit breakers when required.

\section{Pressure EfFECt ON ElECtricAl BREAKDOWN, PARTIAL DISCHARGES AND CORONA}

Partial discharges (PDs) are low intensity electrical discharges which partly bridge the insulation of electric/electronic equipment exposed to intense electric field stress [18]. Corona discharges, a type of PDs, are generated in gaseous dielectrics under a non-uniform electric field conditions, producing an incomplete electrical breakdown of the gaseous gap between electrodes, since the electric field strength is not sufficient to produce complete electrical breakdown [19]. Discharge activity deteriorate electrical and mechanical properties of the insulation material because of the induced chemical reactions [12] that that tend to change the chemical nature and erode insulation materials [20], thus eventually leading to arc tracking or complete breakdown [4]. Tracking deteriorates the dielectric properties of the insulation

material because of the overheating generated by a bombardment of the electrons generated by the discharge and accelerated by the intense electric field [14], hence creating conductive carbon paths along the surface. As a result, micro electrical arcs can grow, which sustain and propagate, thus further damaging the solid insulation [21]. Therefore, arc tracking poses a critical risk for the safety of solid insulation materials of aeronautics electrical/electronic systems [4].

Corona inception voltage (CIV) is the lowest voltage value at which continuous corona activity occurs when gradually increasing the applied voltage. Corona extinction voltage (CEV) is the highest value of the voltage at which the continuous corona discharge disappears when gradually reducing the applied voltage from an initial voltage value that generates corona. This work deals with the CEV instead of the CIV value, since the former is lower than the latter, representing the lowest voltage level that generates corona activity. CIV, $\mathrm{CEV}$ and flashover inception voltages decrease with pressure [3], [5]. There are few scientific works analyzing in detail PD or corona and specifically, arc tracking effects in low pressure aeronautic applications [4], in part due to the specificity of such application, and in part due to the difficulty to characterize and reproduce arc tracking under laboratory conditions [22]. PD measuring systems in accordance with the IEC 60270 standard [23], which also allow detecting corona, usually include a coupling device, transmission system (optical link or connecting cable) and a measuring instrument. According to the IEC 60270, PD and corona can be detected by means of several methods taking advantage of the acoustic, electromagnetic, optical, or chemical reactions produced [23]. PDs and corona are usually detected by utilizing specific instruments, including PD detectors, optical spectrophotometers [24], acoustic sensors [25], radio interference voltage detectors, or radio frequency, VHF and UHF sensors [26], among others, although most of these methods do not allow a direct localization of the discharge points. Table I summarizes most of the existing methods to detect PD and corona occurrence.

TABLE I

PD AND CoRona SENSORS For DifFeRENT APPLICATIONS [23], [27], [28

\begin{tabular}{|c|c|}
\hline Sensing type & Applications \\
\hline \multicolumn{2}{|c|}{ Electrical methods } \\
\hline Radio disturbance meters & Insulators, connectors, transformers, cables \\
\hline UHF sensors & $\begin{array}{l}\text { Power transformers, power cables, gas } \\
\text { insulated substations (GIS) }\end{array}$ \\
\hline HF/VHF sensors & $\begin{array}{l}\text { Power cables, power transformers, corona } \\
\text { discharges }\end{array}$ \\
\hline Inductive methods & $\begin{array}{l}\text { Rotating machines, oil filled transformers, } \\
\text { shielded cables }\end{array}$ \\
\hline Capacitive methods & Switchgear, dry type transformers \\
\hline Low inductive resistors & $\begin{array}{l}\text { Leakage current measurement due to surface } \\
\text { and corona discharges }\end{array}$ \\
\hline \multicolumn{2}{|c|}{ Non electrical methods } \\
\hline Acoustic sensors & $\begin{array}{l}\text { Gas insulated switchgear or oil immersed } \\
\text { equipment such as transformers, unshielded } \\
\text { cables }\end{array}$ \\
\hline Optical sensors & $\begin{array}{l}\text { Power transformers, GIS, surface and corona } \\
\text { discharges in connectors, splices, cables, } \\
\text { insulators, etc. }\end{array}$ \\
\hline UV sensors & Surface discharges and corona \\
\hline $\begin{array}{l}\text { Chemical sensors (ozone, } \\
\text { hydrogen) }\end{array}$ & $\begin{array}{l}\text { Oil- or gas-insulated devices, surface } \\
\text { discharges like corona }\end{array}$ \\
\hline
\end{tabular}


This paper compares three sensors to monitor corona occurrence, i.e., by monitoring the leakage current, which is directly related to the ionization produced by the discharges [3], the generated electromagnetic waves and the visual and ultraviolet (UV) light emitted by the discharges. These sensing methods have been selected since they require simple, low-cost, small-size and lightweight sensors, while being compatible with aircraft environments.

The analysis of leakage current (LC) has been effectively applied to detect and characterize partial discharges in glass insulators under AC supply [29] and also to analyze and monitor the flashover behavior of ice-covered ceramic suspension insulators [30]. It is known that under discharge activity, the LC undergoes different stages, thus changing the shape of the current waveform and its harmonic content [12].

Different types of antennas as sensors have been used to detect PD occurrence and also to localize the source of such discharges, although in the latter case, to accurately measure time differences of arrival (TDOA) of the PD signals required for an accurate localization of the source, the UHF band can be analyzed [31], [32]. Antennas to detect PD activity have appealing features since they allow a non-invasive, continuous, and non-expensive monitoring of PD activity [11]. Radio frequency (RF) antennas can be applied for condition monitoring of $\mathrm{HV}$ insulation systems through PD detection. However, monitoring and localization accuracy tend to be adversely affected because of noises and interferences superimposed with the RF signals, so there is a need to apply denoising algorithms [33]. RF antennas have been used to detect electromagnetic waves generated by corona and PD from transmission lines [34], switchgear [35], cables or transformers [36], among others. By using specific antenna array configurations can also locate the discharge points [18] by measuring the attenuation of the radio frequency signals [35].

Corona detection methods based on visible light are becoming attractive due to the advances in photoelectric detection methods because the colorimetric information informs about the spatial distribution and the status of the discharge [37]. In [38] a micro $\mathrm{Si}$ photomultiplier sensor, sensitive to the visible and UV spectra, is used to detect PDs in $\mathrm{SF}_{6}$ gas. In [39] an optical fiber sensor is applied in gasinsulated-switchgear to detect the acoustic emission generated by PD activity, while [40] provides a method for identifying and classifying partial discharges using frequency domain signal processing of acoustic emission samples.

Relative air density (RAD), which depends on atmospheric pressure $P$ and thus on the altitude $h$ above sea level, highly influences $\mathrm{CEV}$ and critical breakdown voltage values [41], [42]. In a lesser extent, other factors such as debris, moisture, vapors, fumes, conductive smoke, or extreme temperatures can also influence CEV and critical breakdown voltage values [43]. The standard atmosphere [44] provides $h$-RAD and $h-P$ relationships, which are summarized in Table I in the range 0$17000 \mathrm{~m}$ above sea level, since this interval covers the typical altitudes of commercial and military aircrafts [3].

Paschen's curves [45] are commonly used to analyze the relationship between the critical disruptive voltage at breakdown and the $p d$ product, i.e., the product of air pressure and the length of the gap. However, Paschen's curves are only applicable to uniform electric field gaps, i.e., between two parallel plates, and they are not valid for pre-arc conditions, i.e., under early PD or corona occurrence. Fig. 1 displays the Paschen's curve for air at $20^{\circ} \mathrm{C}$, from where it can be deduced that for a constant air gap length under uniform field conditions, the minimum breakdown voltage increases with pressure, although at very low pressure, it also growths rapidly. From Fig. 1 it is also deduced that the dielectric strength of air greatly diminishes with the atmospheric pressure, so for a given voltage value, disruptive discharges are more likely to occur at higher altitudes.

TABLE I

STANDARD ATMOSPHERE ACCORDING TO ISO 2533:1975

\begin{tabular}{cccc}
\hline$h[\mathrm{~m}]$ & $T\left[{ }^{\circ} \mathrm{C}\right]$ & $P[\mathrm{~Pa}]$ & $\mathrm{RAD}[-]$ \\
\hline 0 & 15.0 & 101325.0 & 1.000000 \\
1000 & 8.5 & 89874.6 & 0.907463 \\
2000 & 2.0 & 79495.2 & 0.821625 \\
3000 & -4.5 & 70108.5 & 0.742140 \\
4000 & -11.0 & 61640.2 & 0.668677 \\
5000 & -17.5 & 54019.9 & 0.600911 \\
6000 & -24.0 & 47181.0 & 0.538528 \\
7000 & -30.5 & 41060.7 & 0.481225 \\
8000 & -37.0 & 35599.8 & 0.428709 \\
9000 & -43.5 & 30742.5 & 0.380692 \\
10000 & -50.0 & 26436.3 & 0.336904 \\
11000 & -56.5 & 22632.1 & 0.297076 \\
12000 & -56.5 & 19330.4 & 0.253737 \\
13000 & -56.5 & 16510.4 & 0.216721 \\
14000 & -56.5 & 14101.8 & 0.185104 \\
15000 & -56.5 & 12044.6 & 0.158101 \\
16000 & -56.5 & 10287.5 & 0.135037 \\
17000 & -56.5 & 8786.7 & 0.115337 \\
\hline \hline
\end{tabular}

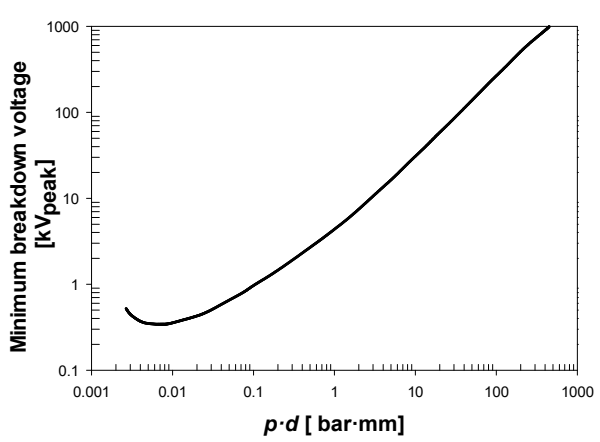

Fig. 1. Paschen's curve obtained for air gaps at $20^{\circ} \mathrm{C}$ with uniform electric field generated between two parallel plates [46][47].

However, since most practical air gaps are non-uniform to some extent, Paschen's curves cannot be directly applied in such cases, whereas PD or corona activity can be generated at lower voltages than those required to form a disruptive discharge [48]. Most of the studies related to PD or corona inception values in low pressure environments are related to HVAC and HVDC transmission lines operating in high altitude regions in countries such as China, Nepal, Bhutan, India or Peru [42]. However, the pressure range analyzed in such studies is insufficient to understand the behavior of the discharges under typical aircraft environments, requiring broader pressure range. For example, in [49], a $5 \mathrm{~cm}$ point-to-plane gap was analyzed in the pressure range $100-70 \mathrm{kPa}$, finding a decrease of the CIV value from $21.0 \mathrm{kV}$ to $16.0 \mathrm{kV}$, respectively. In [50] the 100-50 $\mathrm{kPa}$ interval was analyzed, concluding that important parameters such as electron, positive ions and negative ions particle density increase obviously due to the pressure decrease. 
In [51] the DC corona behavior of transmission lines bundle conductors operating at a pressure range $100-65 \mathrm{kPa}$ was analyzed using an ultraviolet corona camera, concluding that the CIV decreases by around $9 \%$ for every $1000 \mathrm{~m}$ altitude increase. A similar study for two-bundle conductors [52] proved that the CIV reduces from $170 \mathrm{kV}$ to $120 \mathrm{kV}$ when the pressure drops from $98.7 \mathrm{kPa}$ to $58.7 \mathrm{kPa}$. In [6] a needle-plane gap under $400 \mathrm{~Hz}$ supply was analyzed in the pressure range $100-33 \mathrm{kPa}$, showing that the CIV value decreases from 2.35 $\mathrm{kV}$ to $1.45 \mathrm{kV}$. In [53] was shown by means of long exposure photographs that the CIV of insulated wires fed at $400 \mathrm{~Hz}$ decreases from $3.7 \mathrm{kV}$ to $1.3 \mathrm{kV}$ when the pressure decreases from $100 \mathrm{kPa}$ to $10 \mathrm{kPa}$. Similarly, in [3], a sphere-plane gap was studied under positive DC supply by means of visible-UV photographs, showing that the CEV decreases from $15.7 \mathrm{kV}$ to $4.2 \mathrm{kV}$ when reducing the pressure from $100 \mathrm{kPa}$ to $20 \mathrm{kPa}$.

\section{EXPERIMENTAL SETUP}

This paper studies the corona onset voltage pattern of a pointto-plane air gap as a function of atmospheric pressure. The analyzed pressures are in the 100-10 kPa range, i.e. between sea level and $16000 \mathrm{~m}$ altitude, respectively, according to the Standard Atmosphere [44], to be compatible with aircraft environments.

A cylindrical chamber made of 18/10 stainless steel was used to reduce the pressure. It has an inner diarneter of $26 \mathrm{~cm}$ and a height of $37.5 \mathrm{~cm}$, which is enough to fit the electrical and electronic components required to produce and detect the electrical discharges. A single stage Bacoeng BA-1 vacuum pump (1/4 HP, $0.085 \mathrm{~m}^{3} /$ minute; $0.8 \mathrm{~Pa}$ ultimate vacuum pressure) was used to reduce the pressure inside the low pressure chamber. Due to safety considerations, i.e., to protect both the operators and the electrical and electronic equipment of unwanted contacts with the high-voltage supply, the low pressure chamber is located inside a box-like metallic Faraday cage which is connected to ground, as shown in Fig. 2.

An adjustable voltage source (Tecnolab RD-6 $10 \mathrm{kV}_{\mathrm{RMS}}, 50$ $\mathrm{mA}_{\mathrm{RMS}}, 600 \mathrm{VA}$ max output power) was used to supply the high voltage to the test sample. The output voltage was measured by means of a resistive 1000:1 voltage divider using a calibrated Velleman DVM892 Digital multimeter. The leakage current was measured by means of a calibrated Fluke 289 True RMS Digital multimeter, as well as with an oscilloscope probe by monitoring the voltage drop across a $620 \Omega 1 \%$ low inductive resistor connected in series with the circuit [54]. A Tektronix MDO3024 oscilloscope (four channels, $200 \mathrm{MHz}, 2.5$ Gsamples/s) was used to acquire the discharge patterns. Both, the voltage measured by the antenna sensor and across the resistor used to measure the leakage current measured with the oscilloscope by means of two voltage probes (Tektronix TPP0250, bandwidth $250 \mathrm{MHz}$, input impedance $3.9 \mathrm{pF} / / 10$ $\mathrm{M} \Omega)$.

The point-to-plane electrode is composed of a vertical tinplated 16 AWG aluminum conductor, with the tip placed 10 $\mathrm{mm}$ above a grounded flat copper plane, as shown in Fig. 3. Point-to-plane gaps have been extensively studied in the literature, being considered as reference air gaps [55]. This specific electrode geometry was used to ensure corona activity in the range $1-3 \mathrm{kV}$, the distribution voltage for next generation hybrid MEA aircrafts, while being compatible with the dimensions of the low pressure chamber.

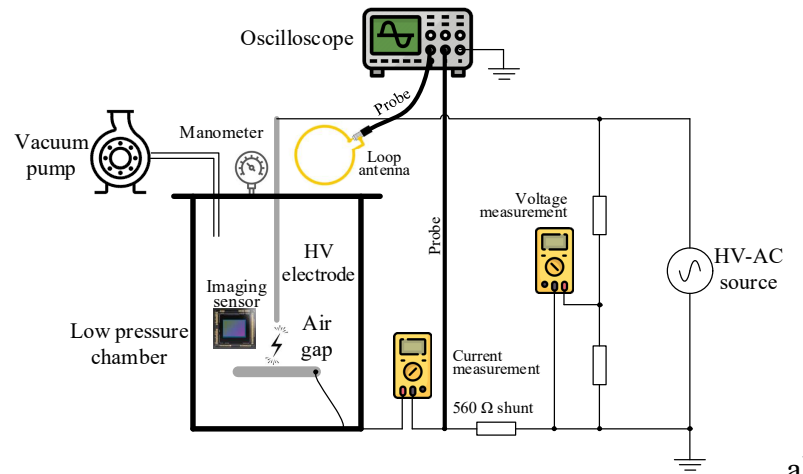

a)

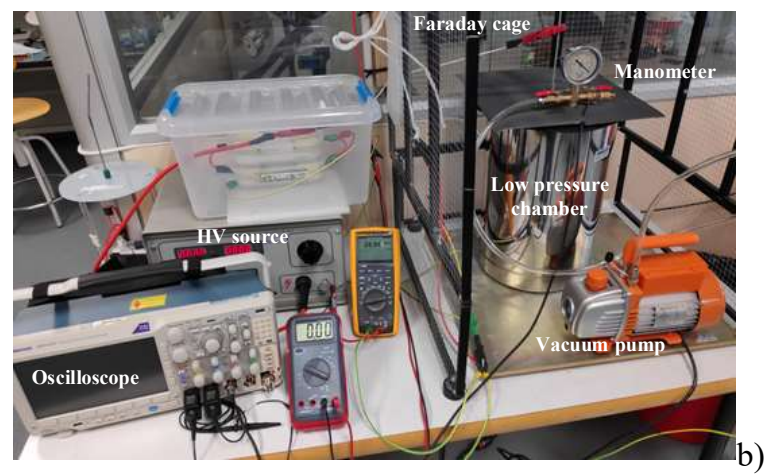

Fig. 2. a) Sketch of the experimental setup and the used instrumentation. b) Actual detail of the Faraday cage in which the experiments are carried out together with the stainless steel vacuum chamber, the single stage vacuum pump, the high-voltage source and the used instrumentation.

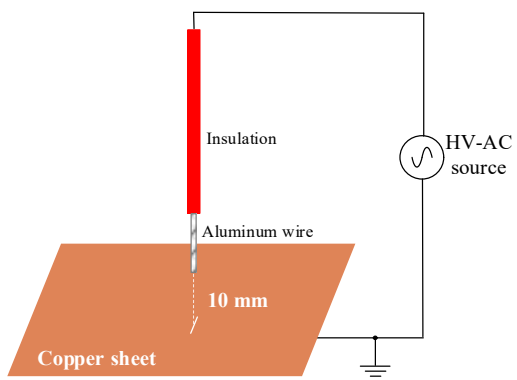

Fig. 3. Detail of the point-to-plane electrode. The tip of the cable is at $10 \mathrm{~mm}$ above the solid copper ground plane.

A 48 MP high resolution and high sensitivity imaging sensor (Sony IMX586 backlit stacked CMOS sensor, resolution $8000 \times 6000$ pixels, sensor size $8.0 \mathrm{~mm}$, unit cell size $0.80 \mu \mathrm{m}$, lens with focal 1.79) was used to acquire visible-UV corona images. Fig. 4 shows the used sensor within its enclosure as well as its bare die version. The corona effect was recorded by means of $32 \mathrm{~s}$ long exposure photographs using ISO 400 sensitivity, automatic white balance and manual focus modes.

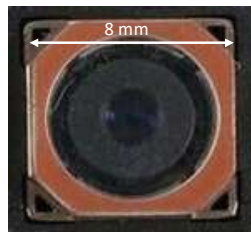

Fig. 4. Detail of the Sony IMX586 backlit stacked CMOS imaging sensor. On the left, the mounted sensor in its enclosure. On the right, the bare die of the sensor. 
A $95 \mathrm{~mm}$ diameter single loop antenna sensor made of enameled wire of $1.2 \mathrm{~mm}$ diameter, was built to measure the radio frequency interference due to the electrical discharges, which is shown in Fig. 5. The perimeter of the loop corresponds to one tenth of the wavelength associated to $20 \mathrm{MHz}$, the approximate cutting frequency of such antenna [56]. The loop antenna was selected due to several advantages, including reduced dimensions, light weight, simple and compact structure and low cost.

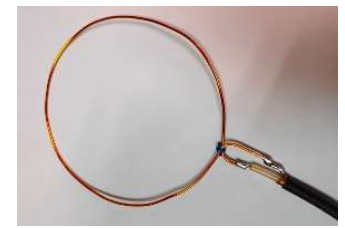

Fig. 5. Single loop antenna (antenna diameter $95 \mathrm{~mm}$, wire diameter $1.2 \mathrm{~mm}$, bandwidth $20 \mathrm{MHz}$ corresponding to 2:1 VSWR, voltage standing wave ratio, using a $50 \mathrm{Ohm}$ termination at the oscilloscope input) used for radio frequency corona detection.

\section{EXPERIMENTAL RESULTS}

This section summarizes the laboratory results obtained by using the experimental setup described in Section IV. The tests were developed in the low pressure chamber with the point-toplane air gap geometry using the three aforementioned sensing methods (LC, antenna and digital camera) by following the next steps: (a) Starting at $0 \mathrm{~V}$, the voltage is gradually increased at an approximate rate of $1 \mathrm{kV} / \mathrm{s}$ up to a voltage level where stabilized discharges are formed. The response of the three sensors are used to verify the occurrence of discharge activity. (b) Decrease the applied voltage while verifying the presence of discharge activity until the CEV value is attained, i.e., the voltage level at which discharge activity disappears.

Fig. 6 shows oscilloscope acquisitions of the electrical discharges under AC supply as recorded by the single loop antenna and the leakage current probe. When increasing the applied voltage, negative corona usually appears before positive corona [55]. However, for a sufficient applied voltage, corona is generated in both semi periods. It is noted that the RMS value of the waveform results almost unchanged because of the low amplitude of the discharges.

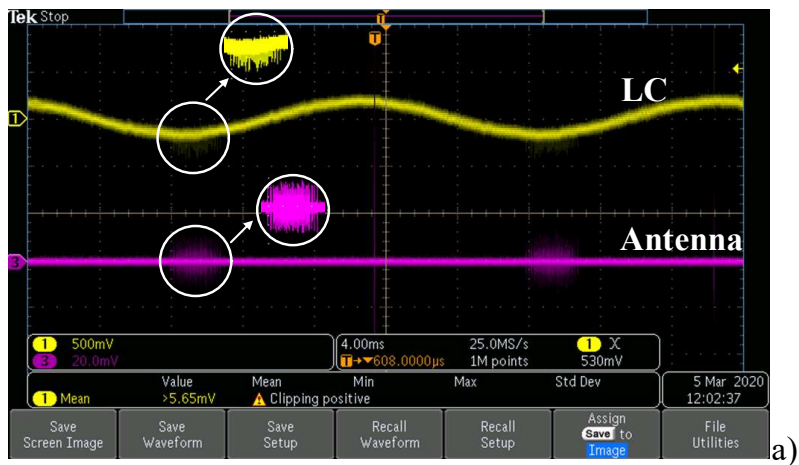

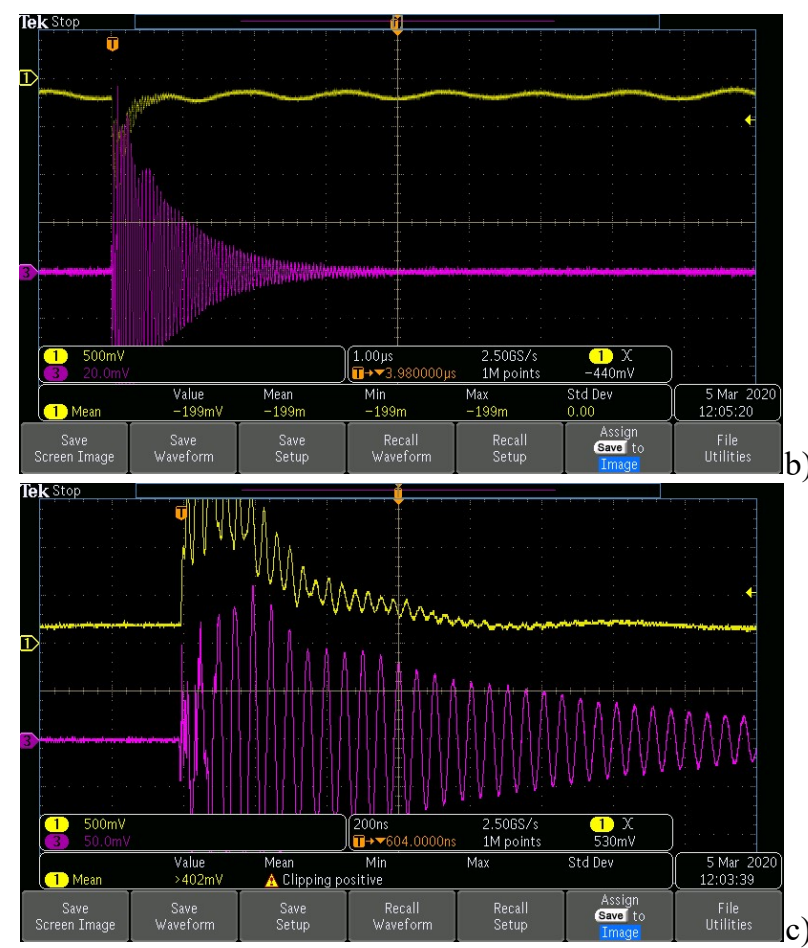

Fig. 6. Partial discharge pulses recorded by the digital oscilloscope at $100 \mathrm{kPa}$ and $3.79 \mathrm{kV}$. The yellow and magenta traces correspond, respectively, to the leakage current and the pulse induced at the single loop antenna. a) Full waveforms. b) Detail of a partial discharge during the negative semi period of the sinewave. c) Detail of a partial discharge during the positive semi period of the sinewave.

Fig. 7 shows the corona discharges recorded by the $48 \mathrm{MP}$ Sony IMX586 backlit imaging sensor, where it is seen that the discharge points can be directly identified and located.

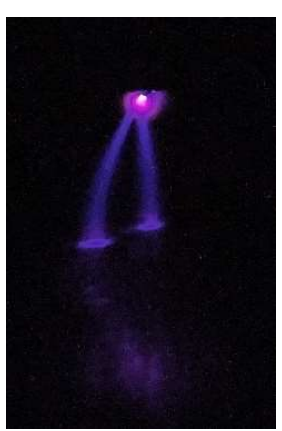

a)

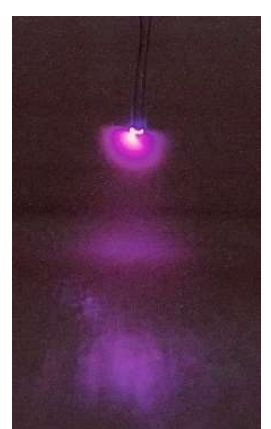

b)

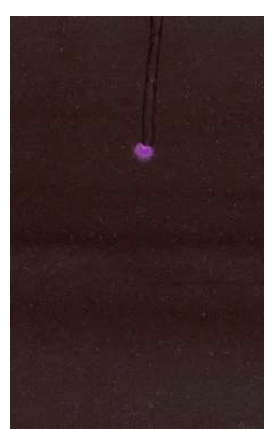

c)
Fig. 7. Localization of the corona discharge points by means of long exposure photographs under AC supply. a) $40 \mathrm{kPa}$ and $2.11 \mathrm{kV}$. b) 10 $\mathrm{kPa}$ and $0.95 \mathrm{kV}$. c) Incipient discharge at $90 \mathrm{kPa}$ and $3.12 \mathrm{kV}$.

Figs. 8 summarizes the results attained with the three sensing systems over the pressure range $0-100 \mathrm{kPa}$ following the procedure detailed in this section. 

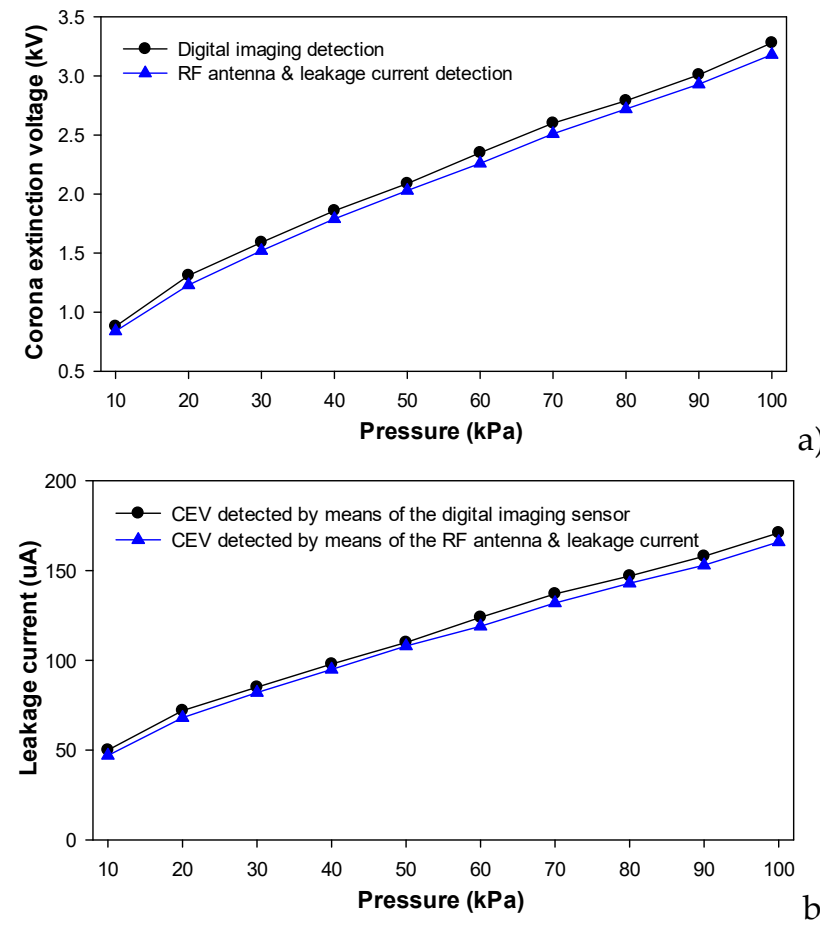

Fig. 8. a) Experimental corona extinction voltage against ambient pressure determined by the digital imaging sensor, the RF antenna and by measuring the leakage current. b) Experimental leakage current against ambient pressure at the corona extinction voltage according to the three sensing methods under CEV conditions.

Results presented in Figs. 8 show, as expected, an obvious decrease of both the CEV (measured with the three sensing systems, i.e., digital imaging sensor, RF antenna and leakage current) and leakage current values when decreasing the pressure. They also show that the sensing methods based on the RF antenna and the measurement of the LC provide identical sensitivity, whereas the sensitivity of the imaging sensor is almost the same. The last method offers the advantage of locating the discharge areas, as shown in Fig. 7, while providing more immunity to external noise and interference. These results also show a quite linear behavior of the CEV values against air pressure.

Table 2 and Table 3 show the main parameters of the linear regressions CEV- $P$ and LC- $P$. As seen, such relationships exhibit a quite linear behavior, so it is easy to predict the CEV and $\mathrm{LC}$ values at different pressures from a measurement in single pressure point.

TABLE 2

MAIN PARAMETERS OF THE CEV Versus AIR PRESSURE LINEAR REGRESSION

\begin{tabular}{lccc}
\multicolumn{4}{c}{ LINEAR REGRESSION } \\
\hline \hline \multirow{3}{*}{ Parameters } & Imaging sensor & Antenna \& LC \\
& Slope $(\mathrm{kV} / \mathrm{kPa})$ & 0.0254 & 0.0251 \\
& Intercept $(\mathrm{kV})$ & 0.7767 & 0.7227 \\
& $R^{2}$ & 0.9923 & 0.9935 \\
\hline \hline
\end{tabular}

TABLE 3

Main PARAmeters Of THE LC Versus Air Pressure LINEAR REGRESSION

\begin{tabular}{lccc}
\multicolumn{4}{c}{ LINEAR REGRESSION } \\
\hline \hline \multirow{3}{*}{ Parameters } & Imaging sensor & Antenna \& LC \\
& Slope $(\mu \mathrm{A} / \mathrm{kPa})$ & 1.2921 & 1.2685 \\
& Intercept $(\mu \mathrm{A})$ & 44.133 & 41.533 \\
& $R^{2}$ & 0.9937 & 0.9930 \\
\hline \hline
\end{tabular}

Finally, Fig. 9 compares the Paschen's curve found in [47] for air with the experimental results obtained with the three sensing methods. Data summarized in Fig. 9 evidences that for large values of the product $p \cdot d$, the CEV value is much below the critical disruptive voltage at breakdown, although, for a given air gap distance $d$, this difference vanishes when reducing the pressure. Therefore, when progressively reducing the pressure, it is more difficult distinguishing between corona and a complete breakdown of the air gap.

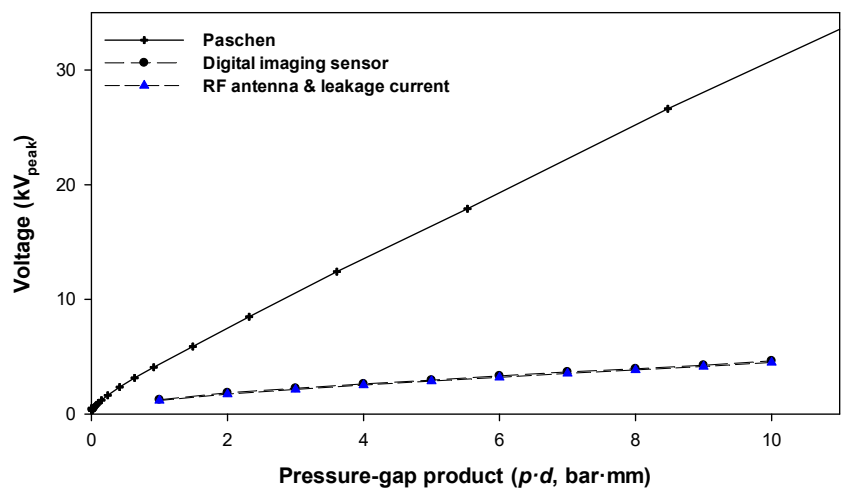

Fig. 9. Comparison between Paschen's curve and the experimental corona curves obtained in this work. Both curves converge at very low pressures, where the corona appearance and the disruptive breakdown become almost undistinguishable.

Fig. 9 has been included for comparison purposes, since Paschen's curve is only valid for uniform field gaps under disruptive breakdown conditions, whereas the results presented in this paper are related to non-uniform fields under corona conditions. Due to its popularity, some manufacturers still refer to Paschen's curve when analyzing the behavior of low pressure air gaps. Fig. 9 evidences that the data presented in this work are much more limiting than those from Paschen's curve.

The results from the experiments sustain the fact that the studied sensors are perfectly capable and usable for an on-line corona monitoring and detection within aeronautic pressure ranges. The corona leakage based monitoring method presents the same detection capabilities as the ones observed with the RF single loop antenna, whereas the visible-UV imaging sensor detection capability is slightly offsetted. The average difference between the CEV values provided by the visible-UV sensor differ by only $3.9 \%$ in average with respect those provided by the other sensing methods.

The sensing methods based on the LC and the antenna provide immediate response when discharge activity is initiated, being the response time a function of the signal processing algorithm carried out to warn of such discharge events. On the contrary, the UV-sensitive imaging sensor requires a long exposure time ( 32 seconds in our experiments), although this is not a drawback, since insulation material degradation due to discharge activity is a relatively long term process. Moreover, the online monitoring and detection of corona using imaging sensors has the clear advantage of providing the physical localization of the discharge areas (see Fig. 7) although the sensor should be carefully located in the most likely place for corona activity, i.e. cable connections or elbows among others. Leakage current based detection as well as RF antenna detection, despite being simple and effective 
detection methods, suffer from the obstacle of being affected by external inferences and noise which may be non-negligible in aircraft environments. This is why such sensors require the application of advanced signal processing algorithms targeting the isolation of discharge events from the rest of the inferring signals in order to raise a warn.

\section{V.CONCLUSION}

The early stage detection of partial discharge and corona activity in electrical and electronic systems becomes an imperative endeavor, especially in those systems found in safety critical applications such as the aircraft industry. Partial discharges, which aggravate with low pressures, are responsible of insulation material degradation, which may lead to catastrophic faults in the form of electric arc tracking, compromising the reliability and functionality of the systems and threatening aircraft safety. The aircraft industry is migrating towards the more electric aircraft (MEA) paradigm in which the electrical/electronic systems will play an even more important role, and due to the required increased voltage levels jointly with the low pressure environments, early discharge detection becomes a key instrument to detect and identify early fault modes.

In this work, an experimental comparison of three methods for incipient corona detection under a wide range of pressure conditions compatible with aircraft environments has been presented. The first of the presented methods is based on an online leakage current monitoring, which instantly reveals the appearance of corona discharge in the form of small amplitude and high frequency peaks over-imposed to the AC waveform. A single loop antenna for RF detection has also been used with promising results. In this case, this phenomenon is manifested in the form of high frequency pulses with decaying amplitude. The detection sensitivity for the single loop antenna is the same as the one seen for the leakage current monitoring. Lastly, a high end $48 \mathrm{MP}$ visible-UV imaging sensor has been to detect corona activity. This sensor allows corona detection with almost the same sensitivity as the two former methods plus the advantage of locating the physical corona inception point. The experiments carried out reveal that the three sensors present a strong linear dependence with respect to pressure in the $10-100 \mathrm{kPa}$ range when determining both the CEV and leakage current as well as enough sensitivity for being used in on-line early corona detection in low pressure applications.

\section{REFERENCES}

[1] R. Rui and I. Cotton, "Impact of low pressure aerospace environment on machine winding insulation," in 2010 IEEE International Symposium on Electrical Insulation, 2010, pp. 1-5.

[2] V. Degardin, L. Kone, F. Valensi, P. Laly, M. Lienard, and P. Degauque, "Characterization of the High-Frequency Conducted Electromagnetic Noise Generated by an Arc Tracking between DC wires," IEEE Trans. Electromagn. Compat., vol. 58, no. 4, pp. 1228-1235, Aug. 2016.

[3] J.-R. Riba, Á. Gómez-Pau, and M. Moreno-Eguilaz, "Experimental Study of Visual Corona under Aeronautic Pressure Conditions Using Low-Cost Imaging Sensors," Sensors, vol. 20, no. 2, p. 411, Jan. 2020.

[4] J.-R. Riba, Á. Gómez-Pau, M. Moreno-Eguilaz, and S. Bogarra, "Arc Tracking Control in Insulation Systems for Aeronautic Applications: Challenges, Opportunities, and Research Needs," Sensors, vol. 20, no. 6, p. 1654, Mar. 2020.

[5] G. G. Karady, M. D. Sirkis, and Li Liu, "Investigation of corona initiation voltage at reduced pressures," IEEE Trans. Aerosp. Electron.
Syst, vol. 30, no. 1, pp. 144-150, 1994

[6] A. N. Esfahani, S. Shahabi, G. Stone, and B. Kordi, "Investigation of Corona Partial Discharge Characteristics Under Variable Frequency and Air Pressure," in 2018 IEEE Electrical Insulation Conference (EIC), 2018, pp. 31-34.

[7] CleanSky, "9th Call for Proposals (CFP09) - List and Full Description of Topics.” Clean Sky, pp. 1-354, 2018.

[8] L. Capineri, G. Dainelli, M. Materassi, and B. D. Dunn, "Partial discharge testing of solder fillets on PCBs in a partial vacuum: new experimental results," IEEE Trans. Electron. Packag. Manuf., vol. 26, no. 4, pp. 294-304, Oct. 2003.

[9] J. Horwath, G. Rhoads, and D. Schweickart, "Corona testing of prototype avionics connectors," in Conference Record of the 1992 IEEE International Symposium on Electrical Insulation, pp. 36-39.

[10] NFPA, "NFPA 921: Guide for Fire and Explosion Investigations," National Fire Protection Agency, Quincy, MA, 2017.

[11] G. V. R. Xavier, E. G. Da Costa, A. J. R. Serres, L. A. M. M. Nobrega, A. C. Oliveira, and H. F. S. Sousa, "Design and Application of a Circular Printed Monopole Antenna in Partial Discharge Detection," IEEE Sens. $J$. , vol. 19, no. 10, pp. 3718-3725, May 2019.

[12] M. A. M. Piah, A. Darus, and A. Hassan, "Leakage current and surface discharge phenomena: Effect on tracking and morphological properties of LLDPE-natural rubber compounds," in Proceedings of the IEEE International Conference on Properties and Applications of Dielectric Materials, 2003, vol. 1, pp. 347-350.

[13] B. X. Du, Y. Liu, and R. L. Wang, "Effects of corona discharge on surface deterioration of silicone rubber insulator under reduced pressures," in 2008 International Symposium on Electrical Insulating Materials (ISEIM 2008), 2008, pp. 271-274.

[14] B. X. Du, Y. Liu, and H. J. Liu, "Effects of low pressure on tracking failure of printed circuit boards," IEEE Trans. Dielectr. Electr. Insul., vol. 15 , no. 5, pp. 1379-1384, Oct. 2008.

[15] A. Pedersen, "On the electrical breakdown of gaseous dielectrics-an engineering approach," IEEE Trans. Electr. Insul., vol. 24, no. 5, pp. 721-739, 1989.

[16] E. Zivanovic, "Analysis of low-pressure DC breakdown in air," 2017, vol. 2017-Octob, pp. 191-194.

[17] A. V. Kozyrev, V. Y. Kozhevnikov, and N. S. Semenyuk, "Theoretical simulation of a low pressure gas breakdown in the gap with combined metal-dielectric electrodes," in Proceedings - International Symposium on Discharges and Electrical Insulation in Vacuum, ISDEIV, 2014, pp. 29-32.

[18] O. El Mountassir, B. G. Stewart, A. J. Reid, and S. G. McMeekin, "Quantification of the performance of iterative and non-iterative computational methods of locating partial discharges using RF measurement techniques," Electr. Power Syst. Res., vol. 143, pp. 110120, Feb. 2017.

[19] M. Tabrizchi and F. Rouholahnejad, "Corona discharge ion mobility spectrometry at reduced pressures," Rev. Sci. Instrum., vol. 75, no. 11, pp. 4656-4661, Nov. 2004.

[20] I. Cotton and A. Nelms, "Higher voltage aircraft power systems," IEEE Aerosp. Electron. Syst. Mag., vol. 23, no. 2, pp. 25-32, Feb. 2008.

[21] V. Degardin, L. Kone, P. Laly, M. Lienard, P. Degauque, and F. Valensi, "Measurement and analysis of arc tracking characteristics in the high frequency band," in AUTOTESTCON (Proceedings), 2016.

[22] T. André, F. Valensi, P. Teulet, Y. Cressault, T. Zink, and R. Caussé, "Arc tracking energy balance for copper and aluminum aeronautic cables," in Journal of Physics: Conference Series, 2017, vol. 825, no. 1.

[23] International Electrotechnical Commission, IEC 60270:2000 Highvoltage test techniques - Partial discharge measurements, 3.0. International Electrotechnical Commission, 2000.

[24] M. Kozioł, Ł. Nagi, M. Kunicki, and I. Urbaniec, "Radiation in the Optical and UHF Range Emitted by Partial Discharges," Energies, vol. 12, no. 22, p. 4334, Nov. 2019.

[25] A. L. Souza and I. J. S. Lopes, "Experimental investigation of corona onset in contaminated polymer surfaces," IEEE Trans. Dielectr. Electr. Insul., vol. 22, no. 2, pp. 1321-1331, Apr. 2015.

[26] C. Zachariades, R. Shuttleworth, and R. Giussani, "A Dual-Slot Barrier Sensor for Partial Discharge Detection in Gas-Insulated Equipment," IEEE Sens. J., vol. 20, no. 2, pp. 860-867, Jan. 2020.

[27] Cigré Working Group D1.33, "Guidelines for unconventional Partial Discharge measurements," Paris (France), 2010.

[28] M. M. Yaacob, M. A. Alsaedi, J. R. Rashed, A. M. Dakhil, and S. F. Atyah, "Review on partial discharge detection techniques related to high voltage power equipment using different sensors," Photonic Sensors, 
vol. 4, no. 4. Springer Verlag, pp. 325-337, 08-Oct-2014

[29] N. A. Othman, M. A. M. Piah, and Z. Adzis, "Space charge distribution and leakage current pulses for contaminated glass insulator strings in power transmission lines," IET Gener. Transm. Distrib., vol. 11, no. 4 , pp. 876-882, Mar. 2017.

[30] Y. Liu, M. Farzaneh, and B. X. Du, "Nonlinear characteristics of leakage current for flashover monitoring of ice-covered suspension insulators," IEEE Trans. Dielectr. Electr. Insul., vol. 23, no. 3, pp. 1242-1250, Jun. 2016.

[31] D. Dukanac, "Application of UHF method for partial discharge source location in power transformers," IEEE Trans. Dielectr. Electr. Insul., vol. 25 , no. 6 , pp. 2266-2278, Dec. 2018.

[32] Y. Hu, Z. Zeng, J. Liu, J. Wang, and W. Zhang, "Design of a Distributed UHF Sensor Array System for PD Detection and Location in Substation," IEEE Trans. Instrum. Meas., vol. 68, no. 6, pp. 1844-1851, Jun. 2019.

[33] A. A. Soltani and A. El-Hag, "Denoising of Radio Frequency Partial Discharge Signals Using Artificial Neural Network," Energies, vol. 12, no. 18 , p. 3485 , Sep. 2019.

[34] Y. Xia, X. Song, Z. Jia, X. Wang, J. Qi, and Z. Xu, "Research on antenna for detecting the corona discharge of transmission line," J. Eng., vol. 2019, no. 16, pp. 2965-2968, Mar. 2019.

[35] C. Pestell, S. Broderick, and D. Caves, "Identification and location of partial discharge in medium voltage switchgear using radio frequency detection techniques," in Petroleum and Chemical Industry Conference Europe Conference Proceedings, PCIC EUROPE, 2017, vol. 2017-May.

[36] C. Yin, H. Wei, F. Kuang, G. Hei, and W. Zhang, "The Design of Planar Rectangular Spiral Antenna for Corona Discharge in Transmission Lines,” J. Phys. Conf. Ser., vol. 1325, pp. 1-7, 2019.

[37] Z. Guo, Q. Ye, F. Li, and Y. Wang, "Study on corona discharge spatial structure and stages division based on visible digital image colorimetry information," IEEE Trans. Dielectr. Electr. Insul., vol. 26, no. 5, pp. 1448-1455, Oct. 2019

[38] M. Ren, J. Zhou, S. Yang, T. Zhuang, M. Dong, and R. Albarracin, "Optical partial discharge diagnosis in SF6 gas-insulated system with SiPM-based sensor array,” IEEE Sens. J., vol. 18, no. 13, pp. 5532-5540, Jul. 2018.

[39] G. M. Ma, H. Y. Zhou, M. Zhang, C. R. Li, Y. Yin, and Y. Y. Wu, “A High Sensitivity Optical Fiber Sensor for GIS Partial Discharge Detection,” IEEE Sens. J., vol. 19, no. 20, pp. 9235-9243, Oct. 2019.

[40] S. Kanakambaran, R. Sarathi, and B. Srinivasan, "Robust classification of partial discharges in transformer insulation based on acoustic emissions detected using fiber bragg gratings," IEEE Sens. J., vol. 18, no. 24, pp. 10018-10027, Dec. 2018.

[41] IEEE, "IEEE Std 4-2013 (Revision of IEEE Std 4-1995) IEEE Standard for High-Voltage Testing Techniques," IEEE Std 4-2013 (Revision of IEEE Std 4-1995). pp. 1-213, 2013.

[42] J.-R. Riba, W. Larzelere, J. Rickmann, J.-R. Riba, W. Larzelere, and J. Rickmann, "Voltage Correction Factors for Air-Insulated Transmission Lines Operating in High-Altitude Regions to Limit Corona Activity: A Review," Energies, vol. 11, no. 7, p. 1908, Jul. 2018.

[43] IEEE, “ANSI/IEEE C37.30-1971. American National Standard Definitions and Requirements for High-Voltage Air Switches, Insulators, and Bus Supports," pp. 1-20, 1971.

[44] ISO, "ISO 2533:1975 - Standard Atmosphere.” pp. 1-11, 1975

[45] F. Paschen, "Ueber die zum Funkenübergang in Luft, Wasserstoff und Kohlensäure bei verschiedenen Drucken erforderliche Potentialdifferenz," Ann. Phys., vol. 273, no. 5, pp. 69-96, 1889.

[46] E. Husain and R. S. Nema "Analysis of Paschen Curves for air, N2 and SF6 Using the Townsend Breakdown Equation," IEEE Trans. Electr. Insul., vol. EI-17, no. 4, pp. 350-353, Aug. 1982.

[47] T. W. Dakin, G. Luxa, G. Oppermann, J. Vigreux, G. Wind, and H. Winkelnkemper, "Breakdown of gases in uniform fields - Paschen's curves for air, N2 and SF6," Elektra, vol. 32, pp. 61-82, 1974.

[48] I. W. McAllister, "Illusory Paschen curves associated with strongly electronegative gases," IEEE Trans. Electr. Insul., vol. 26, no. 3, pp 391-397, Jun. 1991.

[49] D. Yu, M. Farzaneh, J. Zhang, L. Shu, W. Sima, and C. Sun, "Properties of Corona Discharge under Positive DC Voltage at Low Atmospheric Pressure," in 2006 IEEE Conference on Electrical Insulation and Dielectric Phenomena, 2006, pp. 393-396.

[50] B. XingMing et al., "The role of low air pressure in the variation of negative corona-generated space charge in a rod to plane electrode," High Volt., vol. 3, no. 2, pp. 126-132, Jun. 2018.

[51] X. Bian, L. Wang, Y. Liu, Y. Yang, and Z. Guan, "High Altitude Effect on Corona Inception Voltages of DC Power Transmission Conductors Based on the Mobile Corona Cage," IEEE Trans. Power Deliv., vol. 28, no. 3, pp. 1971-1973, Jul. 2013.

[52] Q. Hu, L. Shu, X. Jiang, C. Sun, S. Zhang, and Y. Shang, "Effects of air pressure and humidity on the corona onset voltage of bundle conductors," IET Gener. Transm. Distrib., vol. 5, no. 6, p. 621, Jun. 2011

[53] A. C. Mermigkas, D. Clark, and A. Manu Haddad, "Investigation of High Altitude/Tropospheric Correction Factors for Electric Aircraft Applications," in Lecture Notes in Electrical Engineering, 2020, vol. 598 LNEE, pp. 308-315.

[54] A. H. A. D. Abeysekara, J. R. S. S. Kumara, M. A. R. M. Fernando, M. P. B. Eakanayake, G. M. R. I. Godaliyadda, and J. V. Wijayakulasooriya, "Remote leakage current detector for identification of insulators discharges," IEEE Trans. Dielectr. Electr. Insul., vol. 24, no. 4, pp. 2449-2458, 2017.

[55] J.-R. Riba, C. Abomailek, P. Casals-Torrens, and F. Capelli, "Simplification and cost reduction of visual corona tests," IET Gener. Transm. Distrib., vol. 12, no. 4, pp. 834-841, Feb. 2018.

[56] F. Rozi and U. Khayam, "Design of circle shaped loop antenna as partial discharge sensor," in Proceedings of 2014 International Conference on Electrical Engineering and Computer Science, ICEECS 2014, 2014, pp. 349-352.

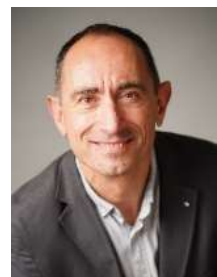

J.-R. Riba (M'09) was born in Igualada, Spain, in 1966. He received the M.S. and Ph.D. degrees in physics from the Universitat de Barcelona, Barcelona, Spain, in 1990 and 2000, respectively. In 1992, he joined the Universitat Politècnica de Catalunya, where currently he is a Full Professor with the Motion Control and Industrial Applications Group. His current research interests include highvoltage engineering, modeling and simulation of electromagnetic devices, data processing and electrical machines

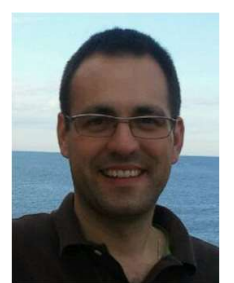

Á. Gómez-Pau received the M.Sc. degree in Engineering from Universitat Politècnica de Catalunya (UPC-BarcelonaTech) and the PhD degree in Electronics Engineering from the same university in 2010 and 2017 , respectively. He is a researcher and an assistant professor at the Electronics Engineering Department at UPC. During his $\mathrm{PhD}$, he has been a visiting scholar at Georgia Institute of Technology, Atlanta, Georgia, USA and University of Eindhoven, Eindhoven, The Netherlands. His research interests focus on test, diagnosis, robustness and reliability of electrical/electronic circuits as well as alternate test methods based on machine learning strategies. Álvaro Gómez is an IEEE Member since 2012.

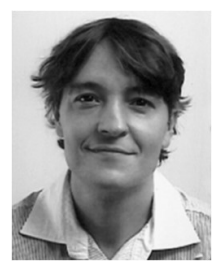

M. Moreno-Eguilaz was born in Logroño, Spain, in 1970. He received the M.S. and Ph.D. degrees in industrial engineering from the Technical University of Catalonia (UPC), Barcelona, Spain, in 1993 and 1997, respectively. He is currently an Associate Professor with the Department of Electronic Engineering, UPC, where he teaches automotive electronics. His current research interests include power electronics, IoT, deep learning, high-voltage engineering and hybrid electric vehicles 